\title{
Influence of heat treatment temperature on bonding and oxidation resistance of diamond particles coated with $\mathrm{TiO}_{2}$ film
}

\author{
XIAO-PAN LIU ${ }^{1,2, *}$, DONG-DONG SONG ${ }^{1}$, LONG WAN $^{1}$, XIAN-BING PANG $^{1}$ and ZHENG LI ${ }^{1}$ \\ ${ }^{1}$ College of Materials Science and Engineering, Hunan University, Changsha 410082, China \\ ${ }^{2}$ Guangdong FengHua Advanced Technology (Holding) Co., Ltd., Zhaoqing 526000, China
}

MS received 26 January 2015; accepted 6 April 2015

\begin{abstract}
In this paper, $\mathrm{TiO}_{2}$ films were coated on the surface of diamond particles using a sol-gel method. The effects of heat treatment temperature on the morphology, composition, chemical bonds, oxidation resistance and compressive strength of diamond particles coated with $\mathrm{TiO}_{2}$ films were characterized through scanning electron microscopy, Fourier transform infrared, Raman spectroscopy, X-ray diffraction analysis, $\mathrm{X}$-ray photoelectron spectroscopy, thermogravimetric-differential scanning calorimetry and compressive strength test. The results showed that when the temperature reached $600^{\circ} \mathrm{C}$, the amorphous $\mathrm{TiO}_{2}$ on the diamond particles surface exhibited as a dense anatase film and the $\mathrm{Ti}-\mathrm{O}-\mathrm{C}$ bond formed between $\mathrm{TiO}_{2}$ and the diamond substrates. When temperature reached $800^{\circ} \mathrm{C}, \mathrm{TiO}_{2}$ films were still in anatase phase and part of the diamond carbon began to graphitize. The graphitizated carbon can also form the $\mathrm{Ti}-\mathrm{O}-\mathrm{C}$ bond with $\mathrm{TiO}_{2}$ film, although $\mathrm{TiO}_{2}$ film would tend to crack in this condition. Meanwhile, the temperature had a serious influence on the oxidation resistance of diamond particles coated with $\mathrm{TiO}_{2}$ films in air. When the heat treatment temperature reached $600^{\circ} \mathrm{C}$, the initial oxidation temperature of the coated diamond particles reached the maximum value of $754^{\circ} \mathrm{C}$. When the diamond particles were oxidized at $800^{\circ} \mathrm{C}$ for $0.5 \mathrm{~h}$ in air, the weight loss rate reached the minimum value of $6.7 \mathrm{wt} \%$ and the compressive strength reached the maximum value of $15.7 \mathrm{~N}$.
\end{abstract}

Keywords. Diamond; $\mathrm{TiO}_{2}$ film; heat treatment temperature; anti-oxidation; mechanical properties.

\section{Introduction}

Due to its extremely high stiffness, diamond is an ideal material for manufacturing tools. When diamond particles and bonding powder are evenly mixed, the diamond tools with a specific shape and strength can be fabricated by the pressing and sintering process. However, the poor thermal stability makes the diamond prone to oxidation in the air and graphitization transition in a protective atmosphere in the sintering process, limiting the service life of diamond tools. ${ }^{1,2}$ Meanwhile, due to the poor wettability between diamond particles and the bonding agent, the surface of diamond usually needs to be coated with films to protect diamond particles from oxidation and graphitization transition. At present, the commonly used approach to surface modification of diamond particles is the electroplating method. By adding a direct current (DC) voltage to the plating solution, metal elements in the vicinity of the cathode are deposited on the diamond abrasive surface. In this way, some metal elements such as $\mathrm{Cr}, \mathrm{Ni}$, $\mathrm{Cu}, \mathrm{Al}$ can be plated on the surface of diamond. But a large number of studies have shown that, ${ }^{3,4}$ due to the

\footnotetext{
*Author for correspondence (liuxiaopanjj@ 126.com)
}

poor physical bonding, metal coating is easily oxidized and prone to fall off during the sintering process of vitrified bond diamond tools. In addition to the poor wettability between metal coating and vitrified bond, the service life of diamond tools had only very limited development.

$\mathrm{TiO}_{2}$ and $\mathrm{TiO}_{2} / \mathrm{Al}_{2} \mathrm{O}_{3}$ films were prepared in previous studies $^{5-7}$ on diamond particles by the sol-gel method. The results showed that, on one hand, a dense $\mathrm{TiO}_{2}$ film on the surface of diamond particles could protect diamond particles from oxidation when it sintered in $\mathrm{O}_{2}$. The incipient oxidation temperature of the $\mathrm{TiO}_{2}$ and $\mathrm{TiO}_{2} / \mathrm{Al}_{2} \mathrm{O}_{3}$ film-coated diamonds in air atmosphere was higher, 150$175^{\circ} \mathrm{C}$, than that of the uncoated diamonds. ${ }^{5-7}$ On the other hand, the $\mathrm{TiO}_{2}$ film could improve the wettability of bond to diamond particles in sintering, which could increase the service life of diamond tools. The grinding ratio of the $\mathrm{TiO}_{2}$ and $\mathrm{TiO}_{2} / \mathrm{Al}_{2} \mathrm{O}_{3}$ film-coated diamonds in air atmosphere was $220-50 \%$ higher than that of the uncoated diamonds. $^{5-7}$ The effects of heat treatment temperature also have a great influence on the morphology, composition, oxidation resistance and compressive strength of diamond particles coated with $\mathrm{TiO}_{2}$ films. However, few studies have been reported on these points.

In this paper, a dense $\mathrm{TiO}_{2}$ film was prepared on the surface of diamond particles by the sol-gel method. We 
further discussed the influence of heat treatment temperatures on the morphology, composition and chemical bonds formed between $\mathrm{TiO}_{2}$ film with diamond, as well as the oxidation resistance of diamond coated with $\mathrm{TiO}_{2}$ films, making it a novel approach for the diamond surface modification.

\section{Experimental}

\subsection{Raw materials}

Raw materials used in this experiment are listed in table 1.

\subsection{Preparation of diamond coated with $\mathrm{TiO}_{2}$ film}

$\mathrm{TiO}_{2}$ sol was prepared using butyl titanate, absolute ethyl alcohol, deionized water and diethanolamine as the starting materials. The chemical composition of aimed $\mathrm{TiO}_{2}$ sol was $\mathrm{Ti}\left(\mathrm{OC}_{4} \mathrm{H}_{9}\right)_{4}: \mathrm{C}_{2} \mathrm{H}_{5} \mathrm{OH}: \mathrm{H}_{2} \mathrm{O}: \mathrm{HN}\left(\mathrm{OC}_{2} \mathrm{H}_{5}\right)_{2}=$ $1: 26.5: 1: 1$ (ratio in mol). The preparation process was as follows: firstly, butyl titanate was dissolved in absolute ethyl alcohol under stirring, followed by the addition of diethanolamine and the solution was mixed until a uniform solution was obtained. Then, a pre-mixed solution of $\mathrm{H}_{2} \mathrm{O}: \mathrm{C}_{2} \mathrm{H}_{5} \mathrm{OH}=1: 10(\mathrm{v} / \mathrm{v})$ was dropped into the uniform solution under severe stirring. Lastly, the mixture was stirred for $1 \mathrm{~h}$ and then kept stable for $24 \mathrm{~h}$ until a pale yellow sol was obtained.

Pre-treatment process of diamond raw material was as follows: firstly, certain amount of diamond particles were placed in a small reagent bottle and soaked in $\mathrm{HCl}$ $\left(1 \mathrm{~mol} \mathrm{l}^{-1}\right)$ for $1 \mathrm{~h}$, then washed with deionized water and dried in an oven to remove all water. After that, it was immersed in an acetone solution for $1 \mathrm{~h}$ accompanied with the ultrasonic cleaning, followed with rinsing of deionized water again and dried in an oven for use.

Preparation process of diamond coated with $\mathrm{TiO}_{2}$ film was as follows: the pre-treated diamond particles were firstly immersed in $\mathrm{TiO}_{2}$ sol for $1 \mathrm{~min}$, and dried for $5 \mathrm{~min}$ at $80^{\circ} \mathrm{C}$ in an oven. This process was repeated three times to obtain the diamond coated with $\mathrm{TiO}_{2}$ film. After this, the further heat treatment was carried out in $\mathrm{N}_{2}$, the sample was dried at $100^{\circ} \mathrm{C}$ for $30 \mathrm{~min}$, and then heated with a heating rate of $5^{\circ} \mathrm{C} \mathrm{min}^{-1}$ to different target temperatures and kept for $1 \mathrm{~h}$ at every target temperature. The diamonds coated with $\mathrm{TiO}_{2}$ films treated at different temperatures were obtained after the natural cooling process after the heating.

\subsection{Characterization}

The morphology of $\mathrm{TiO}_{2}$ film on the diamond particle's surface was imaged with a JSM-6700F scanning electron microscope (SEM) produced by Japan Electronics Corporation. Infrared absorption spectra of diamond particles coated with $\mathrm{TiO}_{2}$ film were measured by the $\mathrm{KBr}$ table method in a Fourier infrared spectrometer (SPECTRUM one). Determined wavenumbers ranged between 4000 and $400 \mathrm{~cm}^{-1}$. Raman spectra of diamond particles coated with $\mathrm{TiO}_{2}$ film was tested with a LABRAM-010 laser confocal Raman spectrometer. The crystalline phase transition of diamond particles coated with $\mathrm{TiO}_{2}$ film was determined using Raman vibration characteristics of the material samples. The wavelength is $514.5 \mathrm{~nm}$, the scanning frequency is 10 and the power on the sample is $5 \mathrm{~mW}$. X-ray photoelectron spectroscopy (XPS) analysis of diamond particles coated with $\mathrm{TiO}_{2}$ film was carried out with the PHI Quantum 2000 type X-ray photoelectron spectroscopy analyzer, with the radiation source of $\mathrm{AlK} \alpha$, experimental vacuum of $10^{-6}(\mathrm{~Pa})$ and the working voltage of $20 \mathrm{eV}$. X-ray diffraction (XRD) analysis of diamond particles coated with $\mathrm{TiO}_{2}$ film was carried out with a D8-ADVANCE X-ray diffractometer (German Brucker Company), with the radiation source of $\mathrm{CuK} \alpha$ radiation, working voltage of $35 \mathrm{kV}$ and working current of $30 \mathrm{~mA}$. Thermogravimetric (TG) analysis of diamond particles coated with $\mathrm{TiO}_{2}$ film was done with the NETZSCH-Thermogravimetric Analysis DIL402PC, with a heating rate of $10^{\circ} \mathrm{C} \mathrm{min}{ }^{-1}$ and an air atmosphere. The test temperature ranged from room temperature to $800^{\circ} \mathrm{C}$. The oxidation starting temperature was determined by the crossing point temperature, where the tangential line of the period of TG curves with the largest inclining rate crossed with the baseline. The oxidation weight-loss experiment was preformed as follows: a certain quantity of samples was placed into ceramic crucibles, and then the ceramic crucibles were transferred into a Muffle furnace,

Table 1. Raw materials used in this experiment.

\begin{tabular}{|c|c|c|c|}
\hline Name & Chemical formula & Purity & Manufacturer \\
\hline Diamond (45/50\#) & $\mathrm{C}$ & Industrial grade & CRIMM superhard materials plant \\
\hline Butyl titanate & $\mathrm{C}_{16} \mathrm{H}_{36} \mathrm{O}_{4} \mathrm{Ti}$ & Chemical pure & Tianjin FuChen Chemical Reagent Factory \\
\hline Diethanolamine & $\mathrm{HN}\left(\mathrm{OC}_{2} \mathrm{H}_{5}\right)_{2}$ & A.R. & $\begin{array}{l}\text { China Pharmaceutical (Group) Shanghai Chemical Reagent } \\
\text { Company Factory, China }\end{array}$ \\
\hline Absolute ethyl alcohol & $\mathrm{CH}_{3} \mathrm{CH}_{2} \mathrm{OH}$ & A.R. & Aetna Fine Chemical Industry Co., Ltd., China \\
\hline Hydrochloric acid & $\mathrm{HCl}$ & A.R. & Zhuzhou Institute of Chemical Industry, China \\
\hline Acetone & $\mathrm{CH}_{3} \mathrm{COCH}_{3}$ & A.R. & Aetna Fine Chemical Industry Co., Ltd., China \\
\hline
\end{tabular}


which was pre-heated to $800^{\circ} \mathrm{C}$. The crucibles were then taken out to measure the residual sample at specified time intervals and then the samples oxidation rates for different oxidation times were calculated. Compressive strength experiment for 45/50 US mesh single diamond particles (Industrial grade, purchased from CRIMM superhard materials plant in China) was carried out with a JLK-rupture strength testing machine produced by Jinwei Measuring Instruments Co., Ltd., in which the diamond particles were oxidized at $800^{\circ} \mathrm{C}$ for $0.5 \mathrm{~h}$ in air. Data of the strength of samples were the result of an average of 10 times determinations.

\section{Results and discussion}

\subsection{Effects of heat treatment temperature on the microstructure and composition of $\mathrm{TiO}_{2}$ films}

Morphologies of $\mathrm{TiO}_{2}$ films on the surface of diamond particles treated at different temperatures are shown in figure 1 .

Figure 1a shows that, before heat treatment, a smooth and uniform film could be observed on the diamond surface. When it was heated at $200^{\circ} \mathrm{C}$, the dehydration and dealcoholization process took place, while this reaction
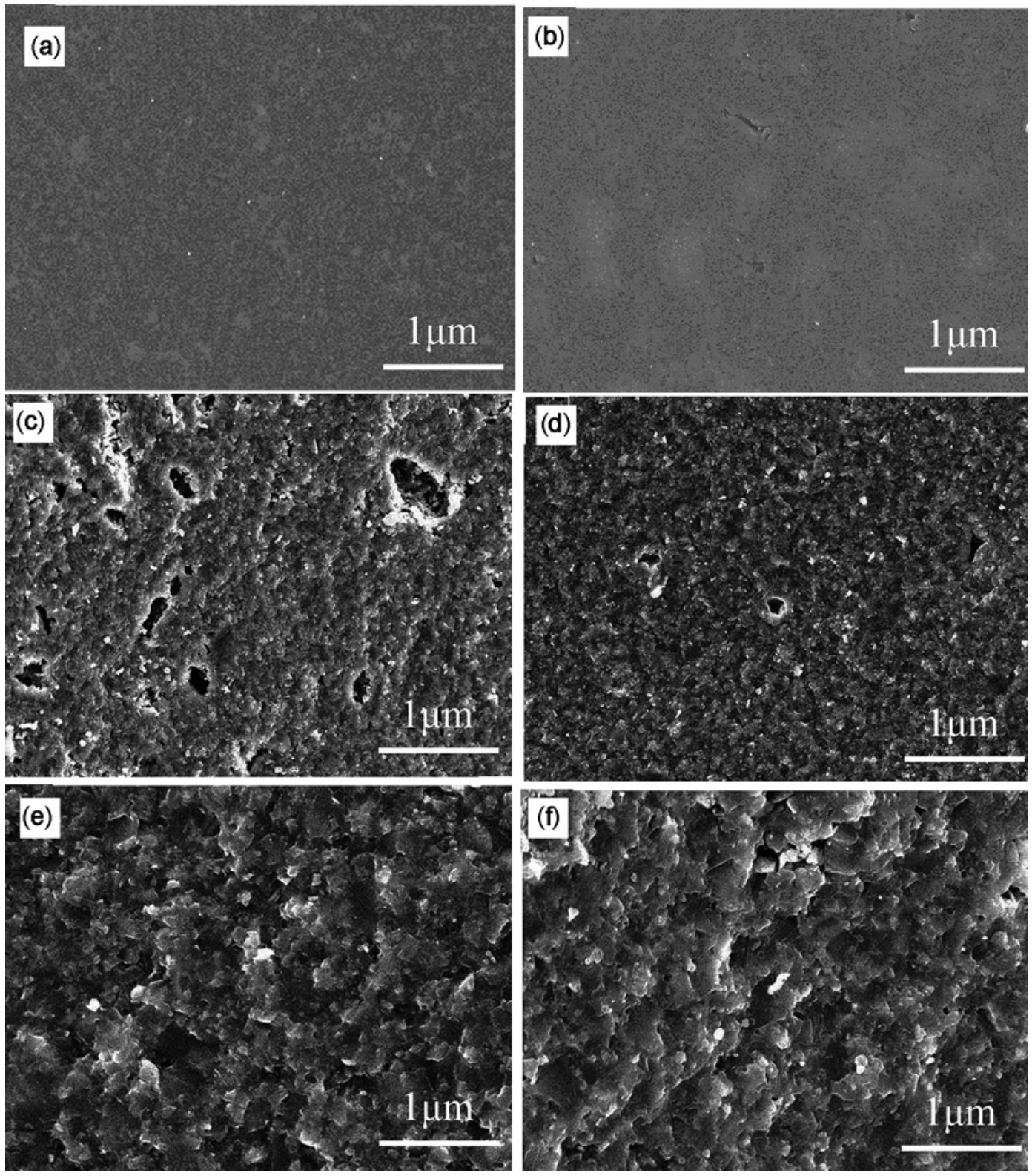

Figure 1. SEM images of $\mathrm{TiO}_{2}$ films coated on diamond particles treated at different temperatures: (a) untreated; (b) $200^{\circ} \mathrm{C}$; (c) $400^{\circ} \mathrm{C}$; (d) $600^{\circ} \mathrm{C}$; (e) $700^{\circ} \mathrm{C}$ and (f) $800^{\circ} \mathrm{C}$. 
did not affect the morphology of the film (figure $1 \mathrm{~b}$ ). When the heat treatment temperature reached $400^{\circ} \mathrm{C}$ (figure 1c), the fine particles could be observed in the film although the film was still continuous. There were also large numbers of pores formed due to the volatilization of structural water. ${ }^{8}$ When treated at $600^{\circ} \mathrm{C}$ (figure $1 \mathrm{~d}$ ), the film was still uniform and dense, which was composed of $\mathrm{TiO}_{2}$ particles ranging between 100 and $300 \mathrm{~nm}$. Figure $1 \mathrm{~g}$ is the sectional view in which the uniform $\mathrm{TiO}_{2}$ film can be observed clearly. After being treated at $700^{\circ} \mathrm{C}$ (figure 1e), the second grain growth occurred and the original small particles among the $\mathrm{TiO}_{2}$ interface began to sinter together and the cracks appeared in the film. After being treated at $800^{\circ} \mathrm{C}$ (figure $1 \mathrm{f}$ ), the sintering phenomenon of $\mathrm{TiO}_{2}$ particles in the film became obvious, the particles grew bigger, and more cracks could be observed in the film.

The XRD patterns of $\mathrm{TiO}_{2}$ film on the surface of diamond particles treated at different temperatures are shown in figure 2. When the temperature was below $400^{\circ} \mathrm{C}, \mathrm{TiO}_{2}$ was amorphous. When it was increased to $600^{\circ} \mathrm{C}$, some weak diffraction peaks of anatase phase appeared. When the temperature further increased to $700^{\circ} \mathrm{C}$, the intensity of diffraction peaks gradually increased; which indicated that the crystalline degree of $\mathrm{TiO}_{2}$ gradually improved. ${ }^{9}$ When at $800^{\circ} \mathrm{C}$, all peaks became sharp, and no crystalline phase transformation emerged. ${ }^{10}$

The Raman spectra of $\mathrm{TiO}_{2}$ film on the surface of diamond particles treated at different temperatures are shown in figure 3 . When the temperature was below $400^{\circ} \mathrm{C}$, no Raman peaks appeared indicating that the $\mathrm{TiO}_{2}$ was amorphous. When the temperature increased to $600^{\circ} \mathrm{C}$, three weak symmetry Raman peaks at 398, 515 and $640 \mathrm{~cm}^{-1}$ were observed, which indicated that the amorphous film began to transit to the anatase phase, while the degree of crystallinity of $\mathrm{TiO}_{2}$ was weak.

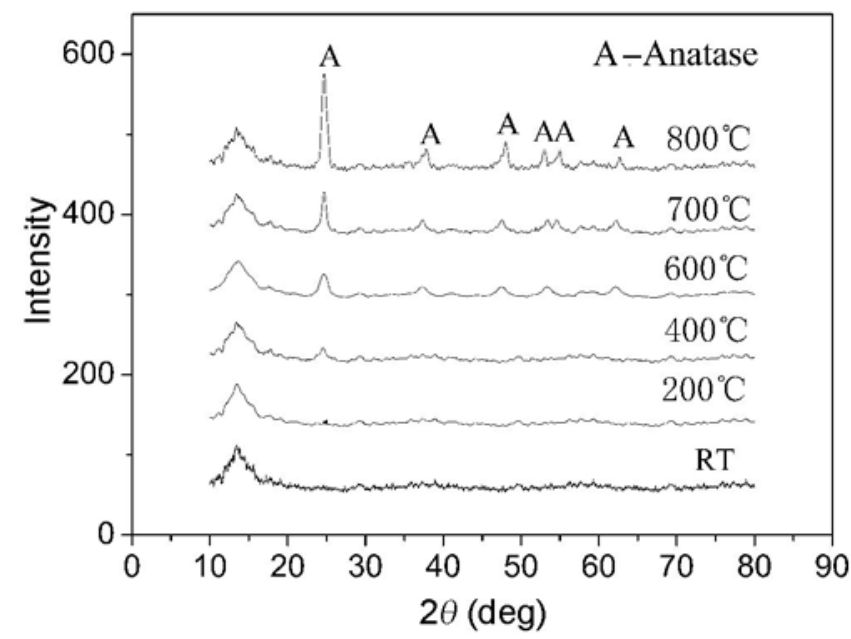

Figure 2. XRD patterns of $\mathrm{TiO}_{2}$ films coated on diamond particles treated at different temperatures.
A further increase of temperature resulted in the high symmetry and gradual enhancement of Raman peaks at 398,515 and $640 \mathrm{~cm}^{-1}$, indicating that both the content and the crystallinity degree of anatase phase in film increased, ${ }^{11}$ which was consistent with XRD results.

\subsection{Effects of heat treatment temperature on the formation process of $\mathrm{TiO}_{2}$ film chemical bonds}

Infrared spectra of diamond coated with $\mathrm{TiO}_{2}$ film treated at different conditions are shown in figure 4. As can be seen, the absorption peaks at $3080-3415 \mathrm{~cm}^{-1}$ in

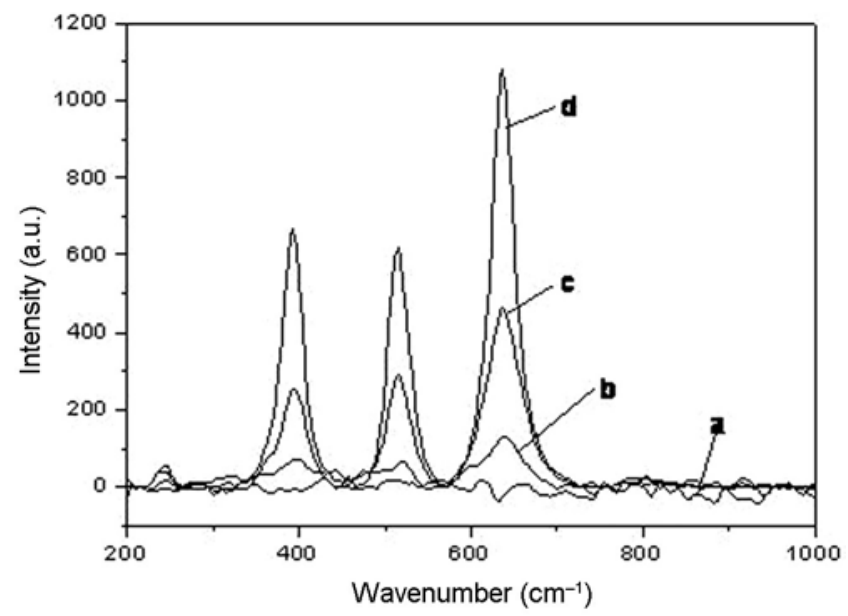

Figure 3. Raman spectra of $\mathrm{TiO}_{2}$ films coated on diamond particles treated at different temperatures: (a) $400^{\circ} \mathrm{C}$; (b) $600^{\circ} \mathrm{C}$; (c) $700^{\circ} \mathrm{C}$ and (d) $800^{\circ} \mathrm{C}$.

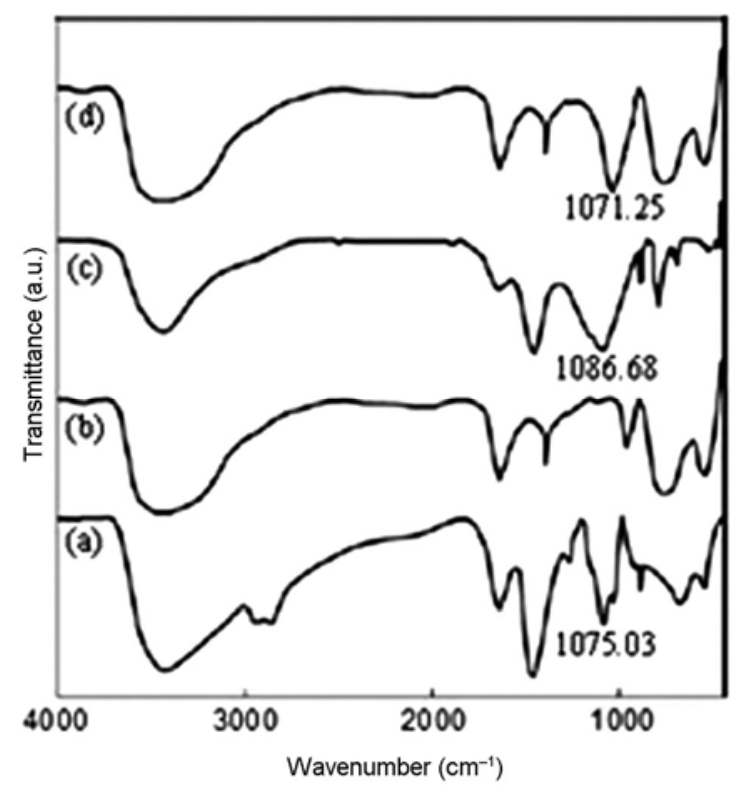

Figure 4. IR spectra of $\mathrm{TiO}_{2}$ films coated on diamond particles treated at different temperatures: (a) $200^{\circ} \mathrm{C}$; (b) $400^{\circ} \mathrm{C}$; (c) $600^{\circ} \mathrm{C}$ and $(\mathbf{d}) 800^{\circ} \mathrm{C}$. 
figure $4 \mathrm{a}-\mathrm{d}$ were corresponding to the $-\mathrm{OH}$ group stretching vibration, owing to the surface-adsorbed water of the particles. Absorption peak at $1639 \mathrm{~cm}^{-1}$ corresponding to $\mathrm{H}-\mathrm{O}-\mathrm{H}$ bending vibration was due to the structure of water. Absorption peak at $1450 \mathrm{~cm}^{-1}$ was caused by $\mathrm{C}-\mathrm{O}$ vibration in $\mathrm{CO}_{3}^{2-}{ }^{6}$ Absorption peak at 2862-2922 $\mathrm{cm}^{-1}$ (figure $4 \mathrm{a}$ ) was due to the bending vibration of methylene $-\mathrm{CH}_{2}-$, which did not appear in other curves, indicating that the organic groups were excluded when temperature reached $400^{\circ} \mathrm{C}$. The absorption peak at $1075 \mathrm{~cm}^{-1}$ (figure $4 \mathrm{a}$ ) represented characteristic vibration of the $\mathrm{Ti}-\mathrm{O}-\mathrm{C}$ bond, which was due to the reaction between $\mathrm{TiO}_{2}$ and free carbon from its surface organic group at $200^{\circ} \mathrm{C}$. When temperature reached $400^{\circ} \mathrm{C}$, most of the free carbon did not form the $\mathrm{Ti}-\mathrm{O}-\mathrm{C}$ bond, resulting in the disappearance of the characteristic peak (figure $4 \mathrm{~b}$ ). After being treated at $600^{\circ} \mathrm{C}$, a strong absorption peak at $1086 \mathrm{~cm}^{-1}$ (figure 4c) appeared, which was caused by the characteristic vibration of $\mathrm{Ti}-\mathrm{O}-\mathrm{C}$ groups and the carbon in this group came from diamond substrate. ${ }^{6}$ This peak moved $10 \mathrm{~cm}^{-1}$ to the left in figure $4 \mathrm{c}$ compared to that in figure $4 \mathrm{a}$, which was due to the change of chemical environment of carbon in $\mathrm{TiO}_{2}$ surface organic group. After being treated at $800^{\circ} \mathrm{C}$, a strong absorption peak at $1071 \mathrm{~cm}^{-1}$ (figure 4d) appeared and was also caused by characteristic vibration of $\mathrm{Ti}-\mathrm{O}-\mathrm{C}$ groups, which moved $5 \mathrm{~cm}^{-1}$ to the right compared to that in figure $4 \mathrm{c}$.

The Raman spectra of diamond coated with $\mathrm{TiO}_{2}$ film treated at different temperatures are shown in figure 5.
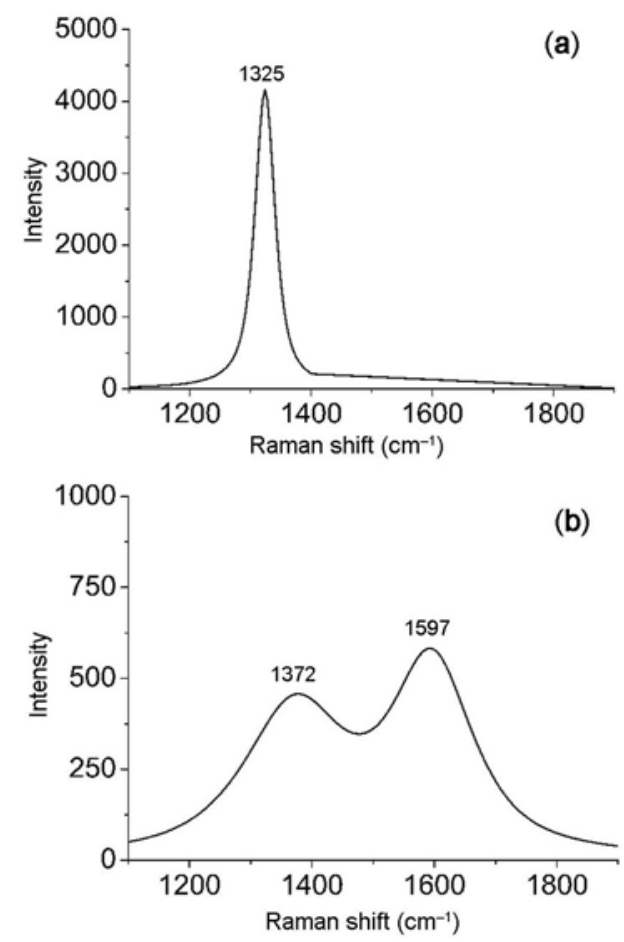

Figure 5. IR spectra of diamond particles coated with $\mathrm{TiO}_{2}$ films treated at different temperatures (a) $600^{\circ} \mathrm{C}$ and (b) $800^{\circ} \mathrm{C}$.
When the temperature was $600^{\circ} \mathrm{C}$, a sharp peak at $1325 \mathrm{~cm}^{-1}$ corresponding to the characteristic vibration peaks of diamond crystal appeared. When increased to $800^{\circ} \mathrm{C}$, broadened characteristic peaks (figure $5 \mathrm{~b}$ ) appeared at 1372 and $1597 \mathrm{~cm}^{-1}$, which were produced by the graphite, diamond, diamond-like carbon and carbon. ${ }^{10}$ Raman spectra indicated that, when the diamond coated with $\mathrm{TiO}_{2}$ film was heat-treated at $800^{\circ} \mathrm{C}$, part of diamond transformed to graphite, and part of graphite $\mathrm{C}$ and Ti elements in $\mathrm{TiO}_{2}$ film formed the Ti-O-C bond. These changes caused the movements of infrared absorption peak. $^{12}$

XPS analysis of Ti element in $\mathrm{TiO}_{2}$ film treated at different temperatures is shown in figure 6 . When treated at $400^{\circ} \mathrm{C}$, large amounts of $\mathrm{Ti}^{4+}$ and $\mathrm{Ti}^{3+}$ and only a small amount of $\mathrm{Ti}^{2+}$ existed in the $\mathrm{TiO}_{2}$ film. When the temperature exceeded $600^{\circ} \mathrm{C}$, large amounts of $\mathrm{Ti}^{4+}$ and $\mathrm{Ti}^{2+}$ film and a small amount of $\mathrm{Ti}^{3+}$ existed in $\mathrm{TiO}_{2}{ }^{13}$ The change of Ti chemical valence was due to the removement of the free carbon in the film, Ti-O-C bond formed between $\mathrm{TiO}_{2}$ film and diamond substrate during this process; thus, the $\mathrm{Ti}^{3+}$ content in the film decreased and $\mathrm{Ti}^{2+}$ content increased.

\subsection{Effects of heat treatment temperature on oxidation resistance and mechanical properties of diamond coated} with $\mathrm{TiO}_{2}$ film

Oxidation weight-loss data of diamond coated with $\mathrm{TiO}_{2}$ film treated at different temperatures are listed in table 2. It can be seen that the temperature of $\mathrm{TiO}_{2}$ film had a great influence on the oxidation resistance of diamond particles. Compared with the uncoated diamond particles, when the temperature reached 200 and $400^{\circ} \mathrm{C}$, the initial oxidation temperature of coated diamond only had a slight improvement (figure 7a), as the large number of pores existed in the film (figure $1 \mathrm{~b}$ and $\mathrm{c}$ ). When it reached

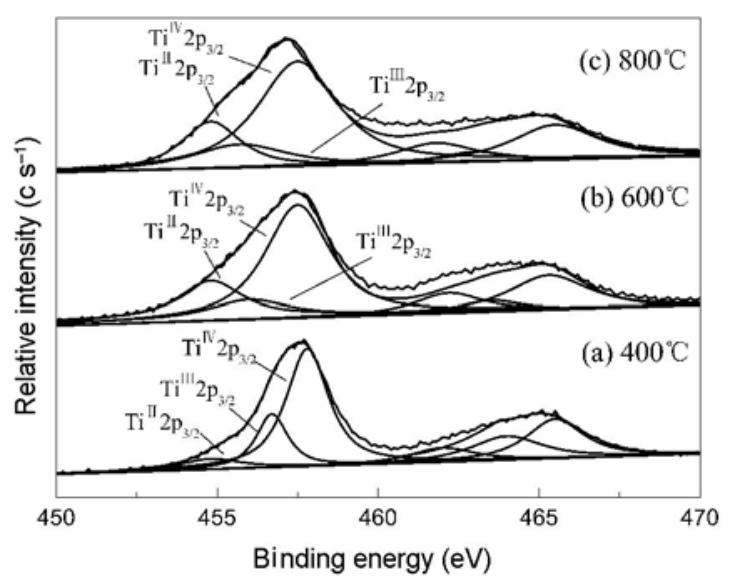

Figure 6. XPS spectra of $\mathrm{Ti}$ in $\mathrm{TiO}_{2}$ films treated at different temperatures: (a) $400^{\circ} \mathrm{C}$; (b) $600^{\circ} \mathrm{C}$ and (c) $800^{\circ} \mathrm{C}$. 
Table 2. Anti-oxidation of diamond particles coated with $\mathrm{TiO}_{2}$ films treated at different temperatures.

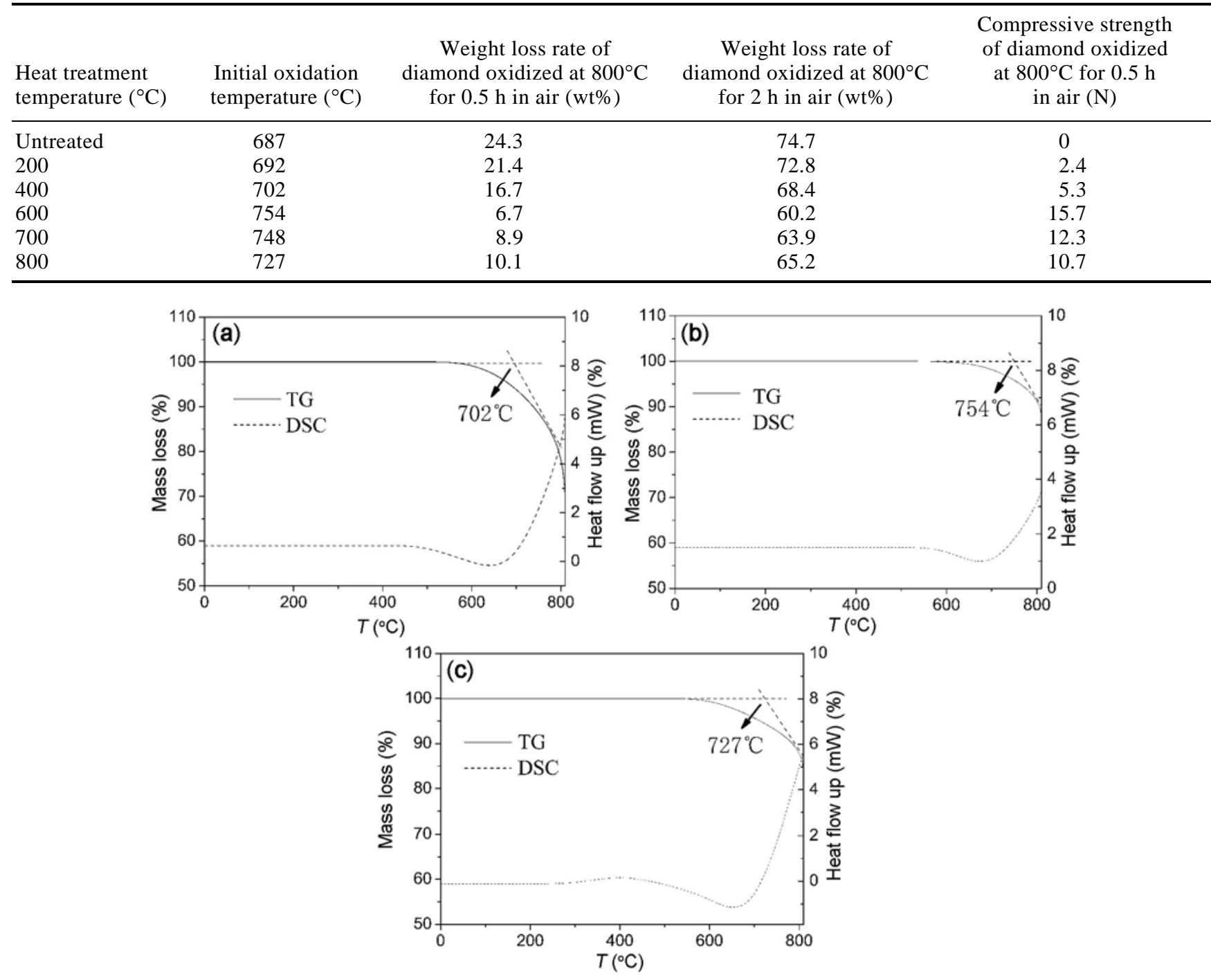

Figure 7. DSC-TG curves of diamond particles coated with $\mathrm{TiO}_{2}$ films treated at different temperatures: (a) $400^{\circ} \mathrm{C}$; (b) $600^{\circ} \mathrm{C}$ and (c) $800^{\circ} \mathrm{C}$.

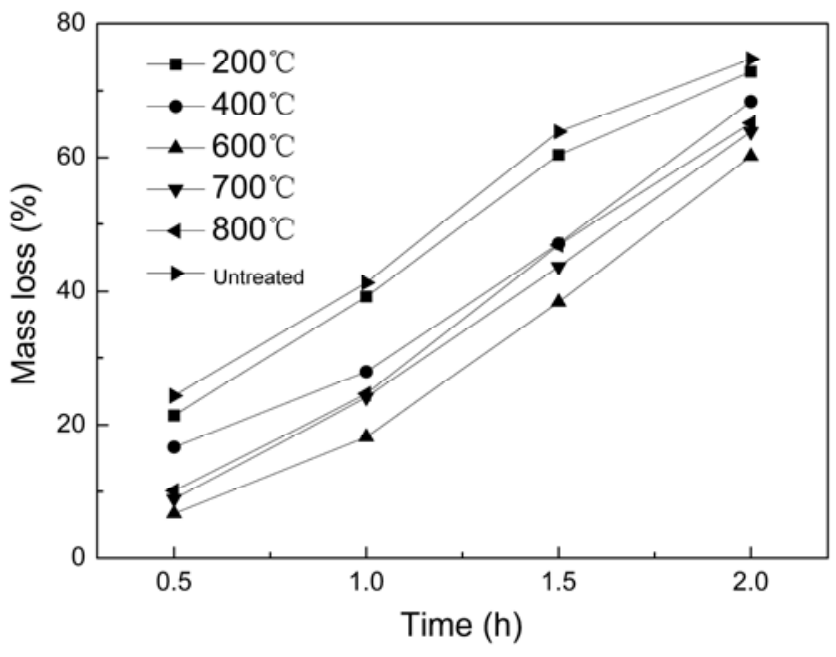

Figure 8. Weight loss of uncoated and coated diamond treated at different temperatures and oxidized at $800^{\circ} \mathrm{C}$ for $2 \mathrm{~h}$ in air. $600^{\circ} \mathrm{C}$, the initial oxidation temperature of coated diamond reached a maximum value of $754^{\circ} \mathrm{C}$ (figure $7 \mathrm{~b}$ ). The obvious improvement might be caused by the dense $\mathrm{TiO}_{2}$ film on diamond surface, which was composed of the fine grain size anatase (figure 1d). When being treated at $800^{\circ} \mathrm{C}$, initial oxidation temperature of diamond dropped to $727^{\circ} \mathrm{C}$ (figure $1 \mathrm{c}$ ), which was caused by the cracks and the decrease of bonding between $\mathrm{TiO}_{2}$ film and diamond (figure 1f).

Before oxidation, the compressive strength of single 45/50\# diamond uncoated with $\mathrm{TiO}_{2}$ film was $24.6 \mathrm{~N}$. As for uncoated diamond particles, when oxidized at $800^{\circ} \mathrm{C}$ for $0.5 \mathrm{~h}$ in air, number of deep cracks and holes generated on the diamond surface owing to the oxidation of diamond (figure 9a), resulting in serious damages to the diamond particles. Then the compressive strength decreased to $0 \mathrm{~N}$. A dense $\mathrm{TiO}_{2}$ film formed on diamond particles surface when the heat treatment 

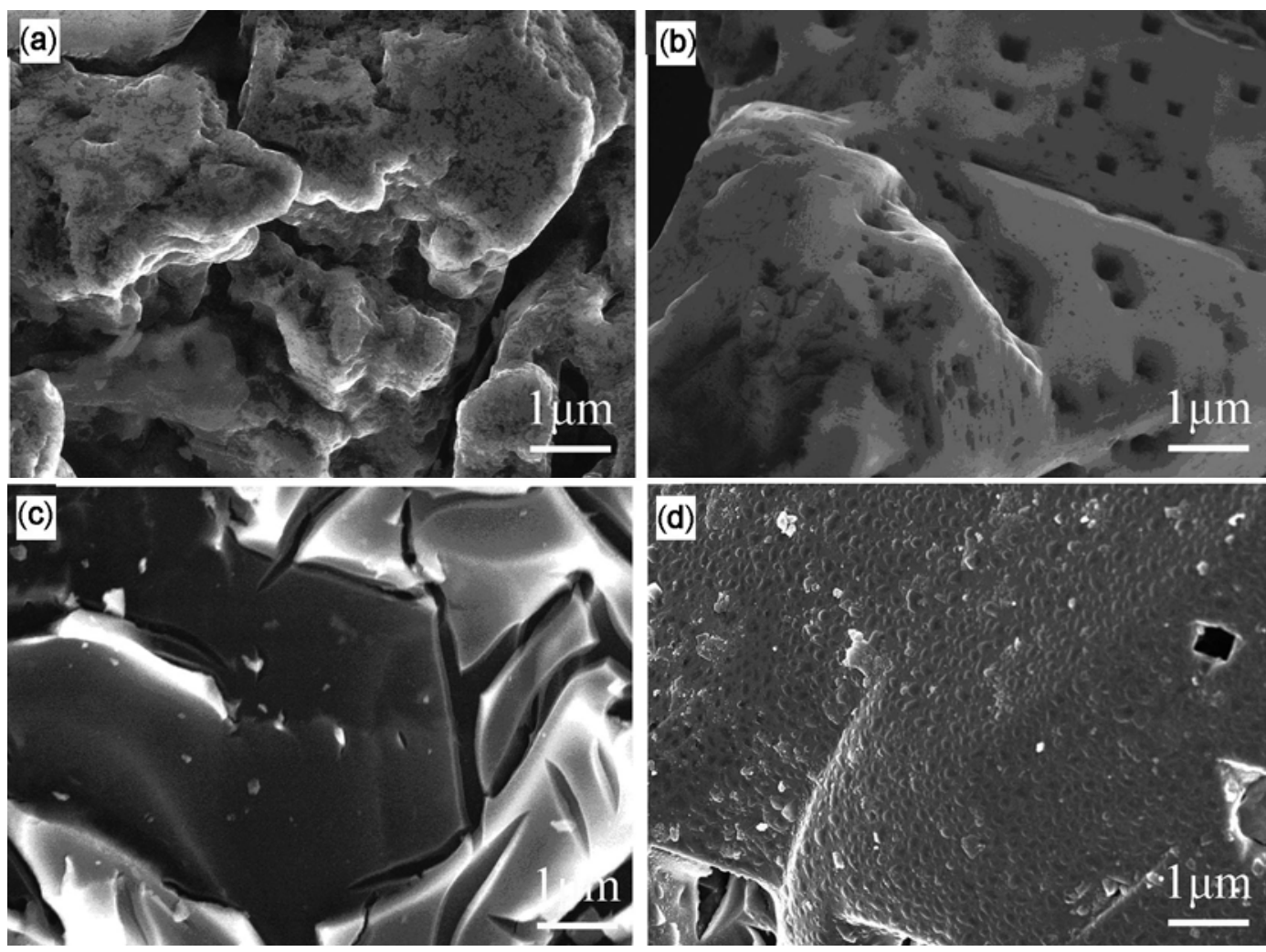

Figure 9. Surface morphology of uncoated and coated diamond treated at different temperatures and oxidized at $800^{\circ} \mathrm{C}$ for $0.5 \mathrm{~h}$ in air: (a) uncoated; (b) $400^{\circ} \mathrm{C}$; (c) $600^{\circ} \mathrm{C}$ and (d) $800^{\circ} \mathrm{C}$.

temperature was $600^{\circ} \mathrm{C}$. It increased the initial oxidation temperature and protected diamond particles from the oxidation. So the compressive strength improved and reached $15.7 \mathrm{~N}$.

The weight-loss curves vs. oxidation time at $800^{\circ} \mathrm{C}$ in the air are shown in figure 8 . As for the sample treated below $600^{\circ} \mathrm{C}$, when the oxidation time was $0.5 \mathrm{~h}$, the mass loss rate decreased with the increase of sample's temperature. When sample's temperature equaled to $600^{\circ} \mathrm{C}$, the mass loss reached the lowest value of $6.7 \mathrm{wt} \%$. When the temperature increased, the mass loss of samples increased.

Figure 9 showed the surface morphology of uncoated and coated diamond treated at different temperatures and oxidized at $800^{\circ} \mathrm{C}$ for $0.5 \mathrm{~h}$ in air. The oxidation corrosion on the surface of uncoated diamond (figure 9a) was serious. Surface of some diamond particles showed deep oxidation corrosion cracks and some particles even broke into pieces. As for the diamond particles coated with $\mathrm{TiO}_{2}$ film and treated at $400^{\circ} \mathrm{C}$ (figure $9 \mathrm{~b}$ ), the oxidation resistance was improved, while cracks appeared in the film and some of them tended to fall off. The particle edges were completely oxidized, and the original smooth surface of the diamond particles showed some steps and circular holes due to the presence of large amounts of screw dislocation defects in diamond, which preferentially reacted with oxygen. ${ }^{14}$ As for the coated diamond treated at $600{ }^{\circ} \mathrm{C}$ (figure $9 \mathrm{c}$ ), continuous $\mathrm{TiO}_{2}$ film still existed on the diamond surface after oxidation, while the film had cracks, some of which tended to fall off. As for the coated diamond treated at $800^{\circ} \mathrm{C}$ (figure 9d), the surface was oxidized into rugged shape. The edges of particles still existed, and the generated spherical particles on the surface were identified to be $\mathrm{TiO}_{2}$ by energydispersive spectroscopy. It could be inferred that, with the increasing oxidation time, $\mathrm{TiO}_{2}$ film on the diamond particles surface tended to fall off completely and was no longer able to protect the diamond surface. Thus when the oxidation time exceeded $0.5 \mathrm{~h}$, the oxidation was obviously accelerated (figure 8).

\section{Conclusion}

Heat treatment temperature has a great influence on the morphology and phase of diamond particles coated with $\mathrm{TiO}_{2}$ film. When temperature was below $600^{\circ} \mathrm{C}, \mathrm{TiO}_{2}$ film was amorphous, and a large number of pores appeared in the film. At $600^{\circ} \mathrm{C}$, the film transformed to a dense anatase phase film. When temperature reached $800^{\circ} \mathrm{C}, \mathrm{TiO}_{2}$ was still in anatase phase, but the cracks emerged in the film.

When the coated diamond particles were treated at $400^{\circ} \mathrm{C}$, there was no bonding formation between $\mathrm{TiO}_{2}$ 
film with diamond, and a large amount of $\mathrm{Ti}^{4+}, \mathrm{Ti}^{3+}$ but only a small amount of $\mathrm{Ti}^{2+}$ existed in the $\mathrm{TiO}_{2}$ film. When the coated diamond particles were treated at $600^{\circ} \mathrm{C}$, $\mathrm{Ti}-\mathrm{O}-\mathrm{C}$ bond formed, and the amount of $\mathrm{Ti}^{2+}$ increased slightly. When being treated at $800^{\circ} \mathrm{C}$, the carbon on the surface of the diamond particles transformed to graphite. The carbon from graphite could also form Ti-O-C bond with $\mathrm{TiO}_{2}$ film.

The heat treatment temperature had a significant influence on the oxidation resistance of diamond particles. When coated diamond particles were treated below $600^{\circ} \mathrm{C}$, the initial oxidation temperature of particles increased with the increase of temperature. When being treated at $600^{\circ} \mathrm{C}$, the initial oxidation temperature of coated diamond particles reached a maximum value of $754^{\circ} \mathrm{C}$. When the diamond particles oxidized at $800^{\circ} \mathrm{C}$ for $0.5 \mathrm{~h}$ in the air, the weight loss rate reached the minimum value of $6.7 \mathrm{wt} \%$ and the compressive strength reached the maximum value of $15.7 \mathrm{~N}$. As the temperature further increased, the initial oxidation temperature of coated diamond particles decreased. When treated at $800^{\circ} \mathrm{C}$, the initial oxidation temperature of diamond decreased to $727^{\circ} \mathrm{C}$.

\section{Acknowledgements}

We thank National Science Foundation of China (Grant no. 51375157) for the grant support to this research.

\section{References}

1. Mamalis A G, Horvath M and Grabchenko A I 2000 J. Mater. Process. Technol. 97120

2. Duan D Z 2012 Nanjing Univ. Aeronaut. Astronaut. China 37

3. Zhong D and Moore J J 2003 Electron. Lett. 6350

4. Dong H F, Lu Y, Li W S, Zhang J and Chu K 2013 Mater. Sci. Eng. Powder Metal. 18125

5. Liu X P, Wan L and Hu W D 2009 Adv. Appl. Ceram. 106501

6. Hu W D, Wan L, Liu X P, Li Q and Wang Z Q 2011 Appl. Surf. Sci. 2575777

7. Hu W D, Wan L, Liu X P, Wang J S and Zhai H C 2012 J. Ceram. Process. Res. 1383

8. Yu K F, Zhao J Z, Tian Y M, Jiang M, Ding X F, Liu Y H, Zhu Y C and Wang Z C 2005 Mater. Lett. 593563

9. Nam C T, Yang W and Duc L M 2013 Bull. Mater. Sci. 36779

10. Peng S G, Xiong S M, Li L H, Tian D and Ai W J 2013 Appl. Surf. Sci. 28713

11. Guang Z G, Li K K, Yang H G and Zhang Y H 2013 Vib. Spectrosc. 68279

12. Liu X P, Qiao A and Wang L 2014 J. Wuhan Univ. Technol. 4319

13. Wahab A K, Bashir S, Al-Salik Y and Idriss H 2014 Appl. Petrochem. Res. 455

14. Lin K H, Peng S F and Lin S T 2007 Int. J. Refract. Met. Hard Mater. 2525 